\title{
PENILAIAN PROGRAM KEAKSARAAN USAHA MANDIRI (KUM) DENGAN MENGGUNAKAN TEKNIK EVALUASI MODEL COIN PRO2 (CONTEXT, INPUT, PROCESS, AND PRODUCT) DALAM RANGKA PENGENDALIAN MUTU PROGRAM PAUDNI
}

\author{
Sadi'in \\ UPT Dinas Pendidikan \\ sadiindindik@gmail.com
}

\begin{abstract}
Abstrak
Karya ilmiah ini ditulis untuk menilai penyelenggaraan program KUM dalam pengendalian mutu program tersebut. Melalui penilaian dengan COIN PRO2 (Context Input Process and Product) diharapkan memperoleh gambaran yang lebih jelas mengenai berbagai permasalahan yang muncul dan upaya pemecahan pada penyelenggaraan program KUM dalam menetapkan langkah perbaikan dan penyempurnaan di masa yang akan datang. Penelitian ini bertujuan mendapatkan deskripsi empirik dan pelaksanaan program KUM yang diselenggarakan PKBM, terkait antara lain tingkat kebutuhan masyarakat akan program KUM dan lingkungan Lembaga PAUD dalam mendukung program KUM, Karakteristik WB, Kepala dan Guru PAUD dan penyelenggara, sarana prasarana, serta program pembelajaran yang dapat mendukung pelaksanaan program KUM, Proses pembelajaran program KUM dan Hasil belajar yang diperoleh warga belajar setelah mengikuti program KUM. Karya ilmiah ini secara teoretis, diharapkan bermanfaat dalam memberikan sumbangan tentang terapan teori, utamanya tentang kesiapan, pelaksanaan dan keefektifan penyelenggaraan program KUM.
\end{abstract}

Kata Kunci: Teknik Penilaian, Program KUM, Evaluasi Model Coin Pro2

\section{Abstrak}

This scientific work was written to assess the implementation of the KUM program in the quality control of the program. Through the assessment with COIN PRO2 (Context Input Process and Product) is expected to get a clearer picture of the various problems that arise and efforts to solve the implementation of KUM program in determining the steps of improvement and improvement in the future. This study aims to obtain empirical description and implementation of KUM program organized by PKBM, related among others the level of community needs for KUM program and PAUD environment in supporting KUM program, WB Characteristics, Head and PAUD Teachers and organizers, infrastructure, and learning programs that can support the implementation of KUM program, KUM program learning process and learning outcomes obtained by residents learn after following KUM program. This scientific work, theoretically, is expected to be useful in contributing the applied theory, particularly on the readiness, implementation and effectiveness of KUM program implementation.

Keywords: Assessment Technique, KUM Program, Evaluation of Coin Pro2 Model

\section{PENDAHULUAN}

Penilik dalam Peraturan Menteri

Negara Pendayagunaan Aparatur

Negara dan Reformasi Birokrasi

Nomor 14 Tahun 2010 adalah tenaga kependidikan dengan tugas utama melakukan kegiatan pengendalian mutu dan evaluasi dampak program PAUDNI. Agar dapat melaksanakan tugas utamanya dalam melakukan kegiatan pengendalian mutu program PAUDNI maka diperlukan pengetahuan dan ketrampilan yang mendukung, sehingga apa yang 
diharapkan dalam Permenpan dan RB dapat berjalan dengan baik.

Perkembangan ilmu

pengetahuan, teknologi dan informasi saat ini terjadi sangat pesat. Pendidikan secara langsung dipengaruhi oleh lingkungan (environment) yang salah satunya adalah perkembangan ilmu pengetahuan, teknologi dan informasi. Perkembangan ilmu pengetahuan dan teknologi akan mempengaruhi proses pendidikan. Lingkungan memberikan masukan (input) terhadap proses pendidikan, sehingga hasil (output) dari pendidikan dapat sesuai dengan perkembangan lingkungan. Penilik memerlukan kompetensi yang secara terus menerus dikembangkan mengikuti perkembangan ilmu pengetahuan, teknologi dan informasi agar mampu melaksanakan kegiatan pengendalian mutu dan evaluasi dampak program PAUDNI secara baik.

Dari hasil pengamatan di lapangan, penyelenggaraan program KUM masih mengalami berbagai masalah. Secara umum permasalahan yang ditemui yaitu terbatasnya sarana prasarana belajar, proses pembelajaran yang belum optimal, dan kurangnya pemahaman Kepala dan Guru PAUD tentang filosofi KUM (Keaksaraan Usaha Mandiri). Penyelenggaraan program KUM yang sudah berjalan sekitar 5 tahun lebih tentunya masih ada kekurangan dan hambatan yang selalu mewarnai perkembangan program. Hambatan, manfaat dan dampak penyelenggaraan program KUM dapat diketahui melalui penilaian terhadap keseluruhan aspek untuk perbaikan di masa yang akan datang.

Karya ilmiah ini ditulis untuk menilai penyelenggaraan program KUM dalam pengendalian mutu program tersebut. Melalui penilaian dengan COIN PRO2 (Context Input Process and Product) diharapkan memperoleh gambaran yang lebih jelas mengenai berbagai permasalahan yang muncul dan upaya pemecahan pada penyelenggaraan program KUM dalam menetapkan langkah perbaikan dan penyempurnaan di masa yang akan datang.

\section{METODE PENELITIAN \\ Setting Penelitian}

Penelitian ini dilaksanakan di Kecamatan Balongpanggang, Kabupaten Gresik, Jawa Timur. Waktu penelitian ini selama 1 bulan yaitu bulan Oktober 2017.

\section{Subjek Penelitian}

Subjek penelitian ini adalah para Kepala dan Guru PAUD serta penyelenggara program KUM yang terlibat langsung dalam program tersebut. Subjek penelitian ini untuk Kepala dan Guru PAUD berjumlah 62 orang.

\section{Teknik dan Alat Pengumpulan Data}

Teknik pengumpulan data berupa kuesioner (angket), observasi, dokumentasi dan wawancara. Sedangkan alat pengumpul data berupa lembar angket, pedoman 
wawancara, pedoman observasi, dan pedoman dokumentasi.

\section{Validasi Data}

Pengukuran validitas diperlukan untuk mengetahui apakah suatu butir instrumen dapat mengukur apa yang seharusnya diukur. Ada dua macam validitas, yaitu validitas isi dan validitas konstruk. Validitas isi merujuk pada derajat empiris dan rasional teoritis, dengan kata lain sejauh mana butirbutir instrumen telah mencakup seluruh isi objek yang hendak diukur.

Validitas konstruk mengarah seberapa jauh instrumen mengukur isi dan makna dari konsep/konstruk teoritik. Validitas konstruk adalah validitas yang didasarkan pada konsep, logika, atau konstruk teoritik. Dengan kata lain, validitas konstruk menunjukkan seberapa jauh suatu instrumen mengukur sifat/bangunan teori tertentu. Alat ukur dikatakan mempunyai validitas konstruk yang tinggi apabila alat tersebut secara logis mampu mengukur konstruk yang seharusnya diukur.

Setelah mengetahui validitas instrumen, langkah berikutnya adalah menghitung reliabilitas instrumen. Reliabilitas diartikan dengan keajegan bilamana tes tersebut diujikan berkalikali hasilnya relatif sama, artinya setelah hasil tes pertama dengan tes berikutnya dikorelasikan terdapat hasil korelasi yang signifikan. Reliabilitas diperoleh dengan cara mengujicobakan satu kali kemudian diestimasi dengan menggunakan formula Koefisien Alpha ( $\alpha$ ) Cronbach untuk mengetahui besarnya koefisien reliabilitasnya. Dari analisis ini dapat diketahui apakah instrumen itu memiliki tingkat kehandalan yang tinggi atau tidak. Tinggi rendahnya instrumen ini secara empirik dibuktikan dengan besarnya koefisien reliabilitas yang diperoleh berdasarkan hasil ujicoba instrumen. Kriteria minimal koefisien reliabilitas instrumen untuk pengukuran kelompok adalah 0,7. Oleh karena itu instrumen yang koefisien reliabilitasnya $\geq 0,7$ dapat dikatakan memiliki keterhandalan dan dapat digunakan untuk mengumpulkan data.

\section{Teknik Analisa Data}

Data yang dikumpulkan dianalisis dengan teknik deskriptif kuantitatif dan kualitatif. Data context yang meliputi kondisi lingkungan program yang terfokus pada permintaan dan dukungan masyarakat terhadap program dilakukan analisis secara naratif. Data input yang berhubungan dengan karakteristik program belajar, WB, Kepala dan Guru PAUD, penyelenggara, dan sarana prasarana pendukung dilakukan analisis deskriptif kuantitatif dan kualitatif.

Data process yang berhubungan dengan aktivitas WB, Kepala dan Guru PAUD dalam mendukung pembelajaran, dilakukan secara deskriptif kuantitatif \& kualitatif. Data product tentang manfaat program dianalisis secara deskriptif kuantitatif. Analisa data yang telah terkumpul dilakukan beberapa 
langkah, yaitu: (1) penskoran jawaban responden, (2) menjumlahkan skor total masing-masing komponen, (3) mengelompokkan skor yang didapat oleh responden berdasarkan tingkat kecenderungan. Penskoran dalam evaluasi ini menggunakan skala 3, yaitu $1 \mathrm{~s} / \mathrm{d}$ 3. Untuk keperluan ini diperlukan meanideal (Mi) dan simpangan baku ideal (Sbi), skor tertinggi dan terendah yang dapat dicapai oleh instrumen sebagai kriterianya. Untuk lebih jelasnya dapat dilihat pada Tabel 1.

Tabel 1. Kriteria penilaian

\begin{tabular}{|c|c|}
\hline Interval Nilai & Interpretasi \\
\hline $\mathrm{X} \geq \mathrm{Mi}+\mathrm{Sbi}$ & Baik \\
$\mathrm{Mi}-\mathrm{Sbi} \leq \mathrm{X}<\mathrm{Mi}+\mathrm{Sbi}$ & Sedang \\
$\mathrm{X}<\mathrm{Mi}-\mathrm{Sbi}$ & Kurang \\
\hline
\end{tabular}

Keterangan:

$\mathrm{X}=$ Skor responden

$\mathrm{Mi}=$ Mean ideal yang dapat dicapai oleh instrumen

Sbi = Simpangan baku ideal yang dapat dicapai instrumen

$\mathrm{Mi}=\frac{\text { skor tertinggi }+ \text { skor terendah }}{2}$

Sbi $=\frac{\text { skor tertinggi }+ \text { skor terendah }}{6}$

Ringkasan hasil perhitungan instrumen evaluasi, dapat dilihat pada Tabel 2 berikut ini.

Tabel 2. Ringkasan Hasil Perhitungan Instrumen Evaluasi

\begin{tabular}{|c|c|c|c|c|c|c|}
\hline No & Aspek yang Dinilai & $\begin{array}{c}\text { Jumlah } \\
\text { Butir }\end{array}$ & $\mathbf{M i}$ & Sbi & Interval Nilai & Interpretasi \\
\hline 1. & $\begin{array}{c}\text { Latar belakang } \\
\text { Lembaga PAUD WB }\end{array}$ & 5 & 10 & 1,67 & $\begin{array}{c}x \geq 11,67 \\
8,33 \leq x<11,67 \\
x<8,33\end{array}$ & $\begin{array}{l}\text { Sesuai sasaran } \\
\text { Cukup sesuai } \\
\text { Kurang sesuai }\end{array}$ \\
\hline 2. & $\begin{array}{c}\text { Motivasi WB } \\
\text { mengikuti program }\end{array}$ & 7 & 14 & 2,33 & $\begin{aligned} x & \geq 16,33 \\
11,67 & \leq x<16,33 \\
x & <11,67\end{aligned}$ & $\begin{array}{c}\text { Tinggi } \\
\text { Sedang } \\
\text { Rendah } \\
\end{array}$ \\
\hline 3. & Aktivitas WB di kelas & 6 & 12 & 2 & $\begin{array}{c}x \geq 14 \\
10 \leq x<14 \\
x<10\end{array}$ & $\begin{array}{l}\text { Baik } \\
\text { Cukup } \\
\text { Kurang } \\
\end{array}$ \\
\hline 4. & $\begin{array}{l}\text { Aktivitas WB } \\
\text { diluar kelas }\end{array}$ & 6 & 12 & 2 & $\begin{array}{c}x \geq 14 \\
10 \leq x<14 \\
x<10\end{array}$ & $\begin{array}{c}\text { Baik } \\
\text { Cukup } \\
\text { Kurang } \\
\end{array}$ \\
\hline 5. & $\begin{array}{c}\text { Aktivitas Kepala dan } \\
\text { Guru PAUD }\end{array}$ & 14 & 28 & 4,67 & $\begin{aligned} x & \geq 32,67 \\
23,33 & \leq x<32,67 \\
x & <23,33\end{aligned}$ & $\begin{array}{c}\text { Baik } \\
\text { Cukup } \\
\text { Kurang } \\
\end{array}$ \\
\hline 6. & Manfaat program & 10 & 20 & 3,33 & $\begin{aligned} X & \geq 23,33 \\
16,67 & \leq X<23,33 \\
X & <16,67\end{aligned}$ & $\begin{array}{l}\text { Besar } \\
\text { Cukup } \\
\text { Sedikit } \\
\end{array}$ \\
\hline
\end{tabular}




\section{HASIL DAN PEMBAHASAN}

\section{Hasil Penelitian}

Penelitian ini ditujukan untuk memberikan informasi dan mendeskrepsikan temuan yang mendalam berdasarkan fakta di lapangan tentang pelaksanaan program KUM di Kecamatan Balongpanggang, apakah sudah sesuai dengan tujuan program atau belum. Deskripsi yang dilakukan berkaitan dengan masalah penilaian yang meliputicontext, input, process pembelajaran, dan product yang dicapai. Secara umum, hasilnya dapat diungkap dalam rangkuman pada Tabel 3 berikut ini.

Tabel 3. Rangkuman Hasil Evaluasi Program KUM di Kecamatan Balongpanggang

\begin{tabular}{|c|c|c|c|c|}
\hline No & $\begin{array}{l}\text { Aspek yang } \\
\text { Dinilai }\end{array}$ & Kriteria & Hasil Evaluasi & Kesimpulan \\
\hline \multirow[t]{2}{*}{1.} & $\begin{array}{l}\text { Context } \\
\begin{array}{l}\text { a. Kebutuhan } \\
\text { masyarakat } \\
\text { thd pro KUM }\end{array}\end{array}$ & $\begin{array}{l}\text { WB mempunyai } \\
\text { keinginan yang tinggi }\end{array}$ & $\begin{array}{l}\text { Dalam mengikuti } \\
\text { program semangat WB } \\
\text { tinggi }\end{array}$ & $\begin{array}{l}\text { Sesuai } \\
\text { kriteria }\end{array}$ \\
\hline & $\begin{array}{l}\text { b. Lingkungan } \\
\text { Lembaga } \\
\text { PAUD WB }\end{array}$ & $\begin{array}{l}\text { Lingkungan Lembaga } \\
\text { PAUD kurang/tidak } \\
\text { mampu }\end{array}$ & $\begin{array}{l}\text { WB berasal dari keluarga } \\
\text { kurang/tidak mampu }\end{array}$ & $\begin{array}{l}\text { Sesuai } \\
\text { kriteria }\end{array}$ \\
\hline 2. & $\begin{array}{l}\text { Input } \\
\text { a. Karakteristik } \\
\text { WB }\end{array}$ & $\begin{array}{l}\text { 1. WB sudah memiliki } \\
\text { SUKMA } \\
\text { 2. Berusia } 15 \text { th ke atas } \\
\text { 3. Mengikuti program } \\
\text { KUM atas keinginan } \\
\text { sendiri }\end{array}$ & $\begin{array}{l}\text { 1. WB sudah memiliki } \\
\text { SUKMA } \\
\text { 2. Usia WB } 40 \text { th ke atas } \\
\text { 3. Ada beberapa WB } \\
\text { mengi kuti program } \\
\text { KUM karena di suruh } \\
\text { Kepala dan Guru } \\
\text { PAUD }\end{array}$ & $\begin{array}{l}\text { Sesuai } \\
\text { kriteria } \\
\text { Sesuai } \\
\text { kriteria } \\
\text { Sesuai } \\
\text { kriteria }\end{array}$ \\
\hline & $\begin{array}{l}\text { b. Karakteristik } \\
\text { Kepala dan } \\
\text { Guru PAUD }\end{array}$ & $\begin{array}{l}\text { 1. Pendidikan mininal } \\
\text { SMP/ Paket B } \\
\text { 2. Pernah mengikuti } \\
\text { pelatihan Kepala dan } \\
\text { Guru PAUD KUM } \\
\text { 3. Pengalaman menjadi } \\
\text { Kepala dan Guru } \\
\text { PAUD minimal } 1 \text { tahun } \\
\text { 4. Menerapkan } \\
\text { pembelajaran } \\
\text { partisipatif } \\
\text { 5. Komitmen terhadap } \\
\text { tugas tinggi }\end{array}$ & $\begin{array}{l}\text { 1. Kepala dan Guru } \\
\text { PAUD berijazah S.1 } \\
\text { dan Paket C } \\
\text { 2. Kepala dan Guru } \\
\text { PAUD pernah ikut } \\
\text { pelati han Kepala dan } \\
\text { Guru PAUD } \\
\text { keaksaraan } \\
\text { 3. Pengalaman Kepala } \\
\text { dan Guru PAUD lebih } \\
\text { dari } 1 \text { tahun } \\
\text { 4. Pembelajaran } \\
\text { partisipatif jarang } \\
\text { dilaksanakan } \\
\text { 5. Komitmen Kepala dan } \\
\text { Guru PAUD terha dap } \\
\text { tugas tinggi }\end{array}$ & $\begin{array}{l}\text { Sesuai } \\
\text { kriteria } \\
\text { Sesuai } \\
\text { kriteria } \\
\text { Sesuai } \\
\text { kriteria } \\
\text { Cukup } \\
\text { sesuai } \\
\text { kriteria } \\
\text { Sesuai } \\
\text { kriteria }\end{array}$ \\
\hline
\end{tabular}




\begin{tabular}{|c|c|c|c|c|}
\hline No & $\begin{array}{c}\text { Aspek yang } \\
\text { Dinilai }\end{array}$ & Kriteria & Hasil Evaluasi & Kesimpulan \\
\hline & $\begin{array}{l}\text { c. Karakteristik } \\
\text { penyelenggar } \\
\text { a }\end{array}$ & $\begin{array}{l}\text { 1. Pendidikan mininal } \\
\text { SMA/Paket C } \\
\text { 2. Pernah mengikuti } \\
\text { pelatihan } \\
\text { penyelenggaraan } \\
\text { program PNF } \\
\text { 3. Pengalaman } \\
\text { penyelenggara } \\
\text { program PNF minimal } \\
1 \text { tahun }\end{array}$ & $\begin{array}{l}\text { 1. Penyelenggara } \\
\text { ijazahnya D.3 } \\
\text { 2. Penyelenggara } \\
\text { pernah mengikuti } \\
\text { pelatihan } \\
\text { penyelenggara } \\
\text { program PNF } \\
\text { 3. Penyelenggara sudah } \\
\text { mempunyai } \\
\text { pengalaman lebih dari } \\
1 \text { tahun }\end{array}$ & $\begin{array}{l}\text { Sesuai } \\
\text { kriteria } \\
\text { Sesuai } \\
\text { kriteria }\end{array}$ \\
\hline & $\begin{array}{l}\text { d. Program } \\
\text { belajar }\end{array}$ & $\begin{array}{l}\text { 1. Materi sesuai dengan } \\
\text { kebutuhan WB } \\
\text { 2. Waktu belajar minimal } \\
3 \times 2 \text { jam dalam } \\
\text { seminggu }\end{array}$ & $\begin{array}{l}\text { 1. Materi sudah sesuai } \\
\text { dgn kebutuhan WB } \\
\text { 2. Pembelajaran } \\
\text { dilaksanakan } 2 \times 3 \text { jam } \\
\text { dlm seminggu }\end{array}$ & $\begin{array}{l}\text { Sesuai } \\
\text { kriteria }\end{array}$ \\
\hline & $\begin{array}{l}\text { e. Sarana dan } \\
\text { prasarana }\end{array}$ & $\begin{array}{l}\text { 1. Tempat mudah } \\
\text { dijangkau WB, Kepala } \\
\text { dan Guru PAUD, dan } \\
\text { penyeleng-gara } \\
\text { 2. Memiliki sarana } \\
\text { pendukung dengan } \\
\text { jumlah yang memadai } \\
\text { \& kondisinya baik } \\
\text { 3. Bahan belajar sesuai } \\
\text { kebutuhan WB } \\
\text { 4. Tersedia bahan \& alat } \\
\text { keterampilan dengan } \\
\text { jumlah memadai } \\
\text { 5. Tersedia administrasi } \\
\text { kejar. }\end{array}$ & $\begin{array}{l}\text { 1. Pembelajaran } \\
\text { dilaksanakan di } \\
\text { rumah kpl dsn \& } \\
\text { rumah Kepala dan } \\
\text { Guru PAUD } \\
\text { 2. Sarana pendukung } \\
\text { seperti meja, kursi, \& } \\
\text { alat tulis kondi-sinya } \\
\text { baik jmlahnya } \\
\text { memadai } \\
\text { 3. Bahan belajar sesuai } \\
\text { dengan kebutuhan } \\
\text { WB } \\
\text { 4. Alat \& bahan } \\
\text { keterampilan } \\
\text { jumlahnya masih } \\
\text { terbatas } \\
\text { 5. Administrasi yang } \\
\text { dimiliki kejar sudah } \\
\text { cukup lengkap }\end{array}$ & $\begin{array}{l}\begin{array}{l}\text { Sesuai } \\
\text { kriteria }\end{array} \\
\text { Kurang } \\
\text { sesuai } \\
\text { kriteria } \\
\text { Cukup } \\
\text { sesuai } \\
\text { kriteria }\end{array}$ \\
\hline 3 & $\begin{array}{l}\text { Process } \\
\text { a. Aktivitas } \\
\text { Kepala dan } \\
\text { Guru PAUD: } \\
\text { 1) Persiapan } \\
\text { mengajar }\end{array}$ & $\begin{array}{l}\text { Membuat rencana } \\
\text { program pembelajaran } \\
\text { dan bahan belajar }\end{array}$ & $\begin{array}{l}\text { Belum semua Kepala } \\
\text { dan Guru PAUD } \\
\text { membuat rencana } \\
\text { pembelajaran dan } \\
\text { bahan belajar }\end{array}$ & $\begin{array}{l}\text { Kurang } \\
\text { sesuai } \\
\text { kriteria }\end{array}$ \\
\hline & $\begin{array}{l}\text { 2) Mengelola } \\
\text { kegiatan } \\
\text { belajar } \\
\text { mengajar }\end{array}$ & $\begin{array}{l}\text { 1. Membuka pelajaran } \\
\text { dengan deskripsi } \\
\text { singkat \& tujuan } \\
\text { instruksional jelas }\end{array}$ & $\begin{array}{l}\text { 1. Kepala dan Guru } \\
\text { PAUD memberitau } \\
\text { tujuan belajar \& } \\
\text { gambaran ten tang } \\
\text { kegiatan yang akan }\end{array}$ & $\begin{array}{l}\text { Sesuai } \\
\text { kriteria }\end{array}$ \\
\hline
\end{tabular}




\begin{tabular}{|c|c|c|c|c|}
\hline No & $\begin{array}{c}\text { Aspek yang } \\
\text { Dinilai }\end{array}$ & Kriteria & Hasil Evaluasi & Kesimpulan \\
\hline & & $\begin{array}{l}\text { 2. Memilih \& } \\
\text { menggunakan media } \\
\text { sesuai materi \& tujuan } \\
\text { 3. Penyajian materi jelas } \\
\text { \& ber urutan disertai } \\
\text { dengan contoh kehi } \\
\text { dupan sehari-hari } \\
\\
\text { 4. Penggunaan metode } \\
\text { pembelajaran yg } \\
\text { sesuai \& bervariasi } \\
\text { 5. Penggunaan alat } \\
\text { peraga yg sesuai dgn } \\
\text { materi belajar } \\
\text { 6. Kepala dan Guru } \\
\text { PAUD menguasai } \\
\text { materi yang } \\
\text { disampaikan } \\
\text { 7. Memberikan } \\
\text { kesempatan kepada } \\
\text { WB utk bertanya \& } \\
\text { mengemukan } \\
\text { pendapat } \\
\text { 8. Memberi perhatian } \\
\text { yang sama pada setiap } \\
\text { WB } \\
\text { 9. Menutup pelajaran } \\
\text { dengan } \\
\text { menyimpulkan \& } \\
\text { meminta umpan balik } \\
\text { WB }\end{array}$ & $\begin{array}{l}\text { dilakukan } \\
\text { 2. Media yang } \\
\text { digunakan cukup } \\
\text { membantu } \\
\text { pemahaman WB } \\
\text { 3. Kepala dan Guru } \\
\text { PAUD dalam } \\
\text { memberikan mate ri } \\
\text { lancar, sistematis, \& } \\
\text { menggu nakan bahasa } \\
\text { yang jelas } \\
\text { 4. Metode yang } \\
\text { digunakan cukup } \\
\text { membantu } \\
\text { pemahaman WB } \\
\text { 5. Sebagian Kepala dan } \\
\text { Guru PAUD belum } \\
\text { menggunakan alat } \\
\text { peraga } \\
\text { 6. Kepala dan Guru } \\
\text { PAUD dapat } \\
\text { menguasai materi } \\
\text { yang diajarkan } \\
\text { 7. Kepala dan Guru } \\
\text { PAUD memberi } \\
\text { kesempatan kepada } \\
\text { WB untuk bertanya \& } \\
\text { mengemukakan } \\
\text { pendapat } \\
\text { 8. Kepala dan Guru } \\
\text { PAUD memberikan } \\
\text { perha tian kepada } \\
\text { semua WB } \\
\text { 9. Kepala dan Guru } \\
\text { PAUD menyimpulkan } \\
\text { materi pembelajaran } \\
\text { \& memberi tugas } \\
\text { kepada WB } \\
\text { mata }\end{array}$ & $\begin{array}{l}\text { Cukup } \\
\text { sesuai } \\
\text { kriteria } \\
\text { Kurang } \\
\text { sesuai } \\
\text { kriteria } \\
\text { Cukup } \\
\text { sesuai } \\
\text { kriteria } \\
\text { Sesuai } \\
\text { kriteria }\end{array}$ \\
\hline & $\begin{array}{l}\text { 3) Pengelolaan } \\
\text { kelas }\end{array}$ & $\begin{array}{l}\text { 1. Kelas tenang \& WB } \\
\text { memperhatikan } \\
\text { 2. Mengatur } \\
\text { penggunaan waktu \& } \\
\text { fasilitas dengan tepat }\end{array}$ & $\begin{array}{l}\text { 1. Masih ada kejar yang } \\
\text { kurang tenang \& ada } \\
\text { beberapa WB yang } \\
\text { kurang } \\
\text { memperhatikan } \\
\text { 2. Sebagian ttr sudah } \\
\text { mengguna kan waktu } \\
\text { \& fasilitas dgn tepat }\end{array}$ & $\begin{array}{l}\text { Cukup } \\
\text { sesuai } \\
\text { kriteria }\end{array}$ \\
\hline
\end{tabular}




\begin{tabular}{|c|c|c|c|c|}
\hline No & $\begin{array}{c}\text { Aspek yang } \\
\text { Dinilai }\end{array}$ & Kriteria & Hasil Evaluasi & Kesimpulan \\
\hline & $\begin{array}{l}\text { 4) Evaluasi } \\
\text { kegiatan } \\
\text { belajar } \\
\text { mengajar }\end{array}$ & $\begin{array}{l}\text { 1. Kepala dan Guru } \\
\text { PAUD melakukan } \\
\text { penilaian selama } \\
\text { berlangsungnya } \\
\text { pembelajaran } \\
\text { 2. Kepala dan Guru } \\
\text { PAUD melakukan peni } \\
\text { laian pada akhir pem } \\
\text { belajaran }\end{array}$ & $\begin{array}{l}\text { 1. Kepala dan Guru } \\
\text { PAUD jarang } \\
\text { memberikan } \\
\text { pertanyaan kepada } \\
\text { WB } \\
\text { 2. Kepala dan Guru } \\
\text { PAUD tidak } \\
\text { melakukan evaluasi } \\
\text { harian }\end{array}$ & $\begin{array}{l}\text { Kurang } \\
\text { sesuai } \\
\text { kriteria }\end{array}$ \\
\hline & $\begin{array}{l}\text { b. Aktivitas WB } \\
\text { 1) Aktivitas di } \\
\text { dalam kelas }\end{array}$ & $\begin{array}{l}\text { 1. WB aktif dalam } \\
\text { mengikuti } \\
\text { pembelajaran } \\
\text { 2. WB saling berinteraksi } \\
\text { 3. Terjadi interaksi dua } \\
\text { arah antara WB deng } \\
\text { an Kepala dan Guru } \\
\text { PAUD }\end{array}$ & $\begin{array}{l}\text { 1. Hanya sebagian kecil } \\
\text { WB yg aktif } \\
\text { berpendapat } \\
\text { 2. Interaksi WB hanya } \\
\text { pada kelompok kecil } \\
\text { 3. Komunikasi umpan } \\
\text { balik antara WB dgn } \\
\text { Kepala dan Guru } \\
\text { PAUD masih kurang }\end{array}$ & $\begin{array}{l}\text { Kurang } \\
\text { sesuai } \\
\text { kriteria } \\
\text { Cukup } \\
\text { sesuai } \\
\text { kriteria } \\
\text { Cukup } \\
\text { sesuai } \\
\text { kriteria }\end{array}$ \\
\hline & $\begin{array}{l}\text { 2) Aktivitas di } \\
\text { luar kelas }\end{array}$ & $\begin{array}{l}\text { 1. WB selalu } \\
\text { mengerjakan tugas } \\
\text { yang diberikan Kepala } \\
\text { dan Guru PAUD } \\
\text { 2. WB mau belajar } \\
\text { mandiri tiap hari } \\
\text { 3. WB mau belajar kelom } \\
\text { pok minimal } 1 \text { kali } \\
\text { seminggu }\end{array}$ & $\begin{array}{l}\text { 1. Sebagian besar WB } \\
\text { mengerja kan tugas } \\
\text { yang diberikan Kepala } \\
\text { dan Guru PAUD } \\
\text { 2. WB belajar mandiri } \\
\text { hanya sebagian kecil } \\
\text { 3. WB yang mau belajar } \\
\text { kelompok hanya } \\
\text { sedikit }\end{array}$ & $\begin{array}{l}\text { Kurang } \\
\text { sesuai } \\
\text { kriteria } \\
\text { Kurang } \\
\text { sesuai } \\
\text { kriteria }\end{array}$ \\
\hline 4 & Product & $\begin{array}{l}\text { 1. WB dapat } \\
\text { mempraktekkan } \\
\text { keterampilan yang } \\
\text { diajarkan oleh Kepala } \\
\text { dan Guru PAUD } \\
\text { 2. Keterampilan yang } \\
\text { diperoleh WB } \\
\text { bermanfaat untuk } \\
\text { kehidupan sehari-hari }\end{array}$ & $\begin{array}{l}\text { 1. WB sudah dapat } \\
\text { mempraktekkan } \\
\text { keterampilan yang } \\
\text { diajarkan oleh Kepala } \\
\text { dan Guru PAUD } \\
\text { 2. Sebagian WB dapat } \\
\text { memanfaatkan } \\
\text { ketrampilanya dlm } \\
\text { kehidupan sehari-hari }\end{array}$ & $\begin{array}{l}\text { Cukup } \\
\text { sesuai } \\
\text { kriteria }\end{array}$ \\
\hline
\end{tabular}

\section{Pembahasan}

\section{Evaluasi Context}

Temuan evaluasi menunjukkan penyelenggaraan program KUM di Kecamatan Balongpanggang mendapatkan respon positif dari masyarakat dan bermanfaat bagi peningkatan keterampilan masyarakat. Program KUM merupakan sebuah program layanan pendidikan yang tepat diberikan kepada warga masyarakat yang telah 
selesai mengikuti program keaksaraan dasar, karena mereka masih membutuhkan layanan pendidikan yang dapat secara langsung memberikan manfaat untuk kelangsungan hidupnya. Pelaksanaan kegiatan pembelajaran yang dilaksanakan sore hari mendukung WB mengikuti proses pembelajaran, karena pada pagi dan siang hari WB harus bekerja mencari nafkah. Melihat adanya kebutuhan masyarakat akan pendidikan yang gratis dan sesuai dengan kebutuhan hidup masyarakat, maka penyelenggaraan program ini perlu dipertahankan dan ditingkatkan kualitasnya. Melalui program seperti ini diharapkan dapat memberikan alternatif pendidikan yang lebih luas bagi masyarakat terutama bagi masyarakat yang berada pada ekonomi lemah.

\section{Evaluasi Input}

\section{Karakteristik Warga Belajar, Kepala} dan Guru PAUD, dan Penyelenggara

Warga belajar yang mengikuti program KUM di kecamatan Balongpanggang adalah perempuan, hal ini disebabkan bahwa orang tua dari keluarga miskin atau kurang mampu lebih mengutamakan pendidikan bagi anak laki-laki sehingga banyak perempuan dari keluarga miskin yang mengalami putus sekolah dasar bahkan ada yang sama sekali tidak sekolah. Latar belakang pendidikan WB program KUM sudah sesuai dengan kriteria yang ditentukan karena sudah mempunyai SUKMA semua, umurnya diatas 40 tahun semua dan dari keluarga miskin atau kurang mampu.

Terkait dengan motivasi WB mengikuti program KUM termasuk dalam kategori tinggi. Motivasi WB mengikuti program KUM pada umumnya disebabkan kebutuhan WB untuk memperoleh keterampilan, baik karena alasan ekonomi maupun waktu pembelajaran sore hari sehingga WB tetap dapat bekerja membantu mencari nafkah keluarga pada pagi dan siang hari. Warga belajar termotivasi mengikuti program KUM karena program ini bisa menambah keterampilan yang dapat digunakan untuk meningkatkan ekonomi keluarga.

Hasil analisis dokumentasi Kepala dan Guru PAUD pada program KUM yang dilaksanakan di kecamatan Balongpanggang menunjukkan bahwa kualifikasi latar belakang pendidikan Kepala dan Guru PAUD sudah memenuhi kriteria, karena secara keseluruhan Kepala dan Guru PAUD sudah berpendidikan minimal SMA atau Paket C. Berdasarkan ketentuan kualifikasi pendidikannya, dapat dikatakan bahwa Kepala dan Guru PAUD program KUM telah memenuhi kualifikasi yang dipersyaratkan. Dilihat dari pengalamannya, berdasarkan data yang diperoleh dalam penelitian ini semua Kepala dan Guru PAUD sudah memenuhi kriteria karena sudah mempunyai pengalaman lebih dari 1 tahun. Selain 
itu, dilihat dari persyaratan mengikuti pelatihan semua Kepala dan Guru PAUD sudah pernah mengikuti pelatihan Kepala dan Guru PAUD program keaksaraan.

Berdasarkan data temuan dalam penelitian ini, diketahui bahwa sebagian besar Kepala dan Guru PAUD yang mengajar pada program KUM adalah guru, sehingga mereka dapat menjalankan tugas mengajarnya dengan baik. Minat Kepala dan Guru PAUD mengajar kejar KUM bukan untuk mendapatkan imbalan jasa, namun untuk membantu pemerintah dalam mengentaskan masalah pendidikan yang ada di masyarakatnya. Dengan demikian Kepala dan Guru PAUD yang mengajar pada program KUM memiliki komitmen tinggi terhadap tugas \& kewajibannya sebagai Kepala dan Guru PAUD yang dilandasi dengan semangat pengabdian.

Hasil analisis data dokumentasi menunjukkan bahwa penyelenggara program KUM di kecamatan Balongpanggang dilihat dari latar belakang pendidikan, pengalaman, dan sebagai penyelenggara dan pengalaman mengikuti pelatihan telah memenuhi kriteria yang ditetapkan. Dari data yang diperoleh, pendidikan penyelenggara adalah Diploma 3, pernah mengikuti pelatihan penyelenggara program dan sudah menjadi penyelenggara lebih dari 1 tahun.

\section{Program Pembelajaran}

Program pembelajaran yang diterapkan pada program KUM disesuaikan dengan kondisi lingkungan sekitar WB. Hal ini mengingat bahwa program KUM diharapkan dapat menghasilkan out put yang dapat meningkatkan taraf hidupnya. Dalam menentukan bahan belajar yang akan digunakan tidak dari pemerintah tetapi berdasarkan kebutuhan WB, disesuikan dengan keterampilan yang dibutuhkan warga belajar terkait dengan kehidupannya sehari-hari.

Materi yang disusun mengacu pada ketentuan yang ditetapkan dengan memperhatikan kondisi lingkungan WB yang ada. Materi berbentuk bahan ajar tematik yang disusun oleh Kepala dan Guru PAUD bersama penyelenggara berdasarkan kemampuan, minat, dan kebutuhan WB. Selain penyesuaian materi pembelajaran, penyesuaian juga dilakukan terhadap waktu belajar. Penyusunan program pembelajaran sesuai dengan kesepakatan antara penyelenggara, Kepala dan Guru PAUD dan WB agar pelaksanaan proses pembelajaran dapat berjalan sesuai dengan yang diharapkan.

Mengingat kondisi WB adalah orang dewasa, penetapan waktu yang demikian tentunya dapat dimengerti dan cukup tepat. Dengan warga belajar yang harus bekerja pada pagi dan siang hari, maka dipilihnya waktu belajar sore hari tentunya merupakan keputusan yang sangat bijaksana. 
Mencermati waktu belajar seperti ini, tentunya dapat dikatakan bahwa waktu belajar pada program KUM sangat terbatas. Oleh karena itu, dengan keterbatasan waktu diperlukan berbagai strategi antara lain perlu didorong terlaksananya belajar mandiri di rumah agar tujuan pembelajaran dapat tercapai.

\section{Sarana dan Prasarana Belajar}

Sarana dan prasarana merupakan salah satu aspek penting pendukung program untuk memperlancar proses pembelajaran. Hasil pengamatan pada program KUM menunjukkan bahwa tempat belajar dan sarana pendukung yang digunakan untuk mendukung kegiatan pembelajaran termasuk kategori baik. Sedangkan administrasi kelompok belajar dan bahan ajar termasuk kategori cukup.

Sarana belajar seperti bahan belajar dan alat keterampilan bila dilihat dari ketersediaannya tidak memiliki perbandingan yang sesuai dengan jumlah WB. Hasil pengamatan di lapangan menunjukkan bahan belajar dan alat keterampilan yang ada jumlahnya belum mencukupi untuk mencapai perbandingan yang ideal antara sarana belajar dengan jumlah WB. Kenyataan ini menjadi masalah tersendiri bila dikaitkan proses pembelajaran yang berlangsung.

\section{Evaluasi Process}

\section{Aktivitas Kepala dan Guru PAUD dalam Proses Pembelajaran}

Evaluasi proses berkenaan dengan aktivitas Kepala dan Guru PAUD dalam proses pembelajaran dinilai dengan menggunakan angket yang diberikan kepada WB. Dengan angket tersebut diharapkan WB dapat menilai aktivitas Kepala dan Guru PAUD dalam proses pembelajaran. Dari pendapat WB tersebut kemudian ditindak lanjuti dengan pengamatan langsung oleh evaluator pada saat pembelajaran berlangsung.

Hasil pengamatan terhadap proses pembelajaran secara umum Kepala dan Guru PAUD masih memperlihatkan beberapa kekurangan yang perlu perbaikan dalam beberapa hal, yaitu persiapan mengajar, membuka pelajaran, penggunaan alat peraga/alat bantu, dan metode belajar. Kewajiban Kepala dan Guru PAUD sebelum mengajar harus membuat rancangan atau rencana pembelajaran dan bahan ajar. Menurut Kepala dan Guru PAUD, tidak dibuatnya rencana pembelajaran dan bahan belajar tersebut dengan alasan penyelenggara tidak pernah menanyakan dan menyarankan untuk membuatnya. Persiapan administrasi juga dirasakan Kepala dan Guru PAUD hanya memberatkan dan tidak memberikan kemanfaatan.

Dalam proses pembelajaran, berdasarkan hasil pengamatan menunjukkan bahwa dari materi yang 
disampaikan, ternyata Kepala dan Guru PAUD belum mampu membangkitkan minat WB untuk mengikuti pembelajaran secara aktif. Upaya Kepala dan Guru PAUD untuk menciptakan suasana belajar yang saling aktif belum terlaksana dengan baik. Hal ini disebabkan karena pada umumnya Kepala dan Guru PAUD dalam proses pembelajaran masih menerapkan pola pengajaran pada sekolah formal, karena sebagian besar Kepala dan Guru PAUD berasal dari guru. Selain itu materi yang diberikan oleh Kepala dan Guru PAUD sedikit bila dikaitkan dengan materi belajar orang dewasa yang banyak belajar dari pengalaman.

Metode yang digunakan Kepala dan Guru PAUD dalam proses pembelajaran kurang bervariasi, hanya terbatas pada penggunaan salah satu metode mengajar. Metode yang sering digunakan oleh sebagian besar Kepala dan Guru PAUD KUM adalah metode ceramah, hanya beberapa saja yang mengkombinasikan dengan model partisipatif. Terbatas nya penggunaan metode tersebut karena sebagian besar Kepala dan Guru PAUD berprofesi guru, sehingga masih kurang memahami berbagai metode mengajar yang ada pada PNF.

\section{Aktivitas Warga Belajar di Kelas dan di Luar Kelas \\ Berdasarkan hasil pengamatan dikelas menunjukkan suasana pembelajar-an cukup lancar,}

pelaksanaan proses pembelajaran sesuai jadwal belajar yang ada. Namun saat berlangsungnya proses belajar, WB terlihat kurang serius mengikuti pelajaran yang disampaikan Kepala dan Guru PAUD. Hal ini terlihat pada saat Kepala dan Guru PAUD memulai menyam-paikan materi masih ada WB yang berbicara. Berdasarkan kenyataan tersebut menunjukkan bahwa pelaksanaan proses pembelajaran berjalan kurang tertib.

Selain itu pada saat pembelajaran berlangsung, diketahui bahwa WB terlihat kurang aktif dalam mengikuti proses pembelajaran. Kekurangaktifan WB terlihat dari kurangnya perhatian terhadap penjelasan yang disampaikan Kepala dan Guru PAUD, ada WB yang sering bicara sesama teman, dan masih banyak ditemui WB yang terlambat datang ke kejar padahal pembelajaran sudah dimulai. Hal ini menyebabkan rendahnya pemahaman WB terhadap materi yang disampaikan Kepala dan Guru PAUD.

Hasil pengamatan tentang kegiatan WB di luar kelas hanya sebagian kecil WB yang berupaya menambah aktivitas belajarnya secara mandiri. Belajar mandiri biasanya dilakukan WB ketika memiliki waktu luang. Tidak semua WB dapat menjalankan belajar mandiri dengan baik, bahkan sebagian WB jarang melakukan belajar mandiri di rumah. Walaupun 
sebenarnya mereka mengerti bahwa belajar mandiri itu diperlukan, akan tetapi mereka biasanya beralasan telah lelah bekerja. Waktu yang mereka miliki telah banyak tersita untuk mencari nafkah dan urusanurusan keluarga. Walaupun Kepala dan Guru PAUD memberikan tugas tambahan terstruktur, sering WB tidak sempat mengerjakannya. Untuk menambah belajar, hanya sebagian kecil WB yang menambah jam belajarnya dengan kegiatan belajar kelompok.

Kondisi ini tentunya kurang mendukung keberhasilan program KUM. Jika kurang optimalnya kegiatan belajar di kelas masih ditambah dengan kurangnya kualitas belajar mandiri di rumah tentunya sangat sulit bagi WB untuk dapat menguasai materi dengan baik. Oleh karena itu, kondisi ini harus segera mendapatkan perhatian, baik dari WB, Kepala dan Guru PAUD, maupun penyelenggara. Warga belajar harus lebih berusaha memaksimalkan belajarnya, baik di kelas maupun di luar kelas, Kepala dan Guru PAUD juga harus berusaha untuk selalu mendorong WB agar lebih baik dalam belajarnya. Dalam hal ini, penyelenggara juga perlu mengingatkan kepada seluruh WB agar meningkatkan kualitas belajarnya.

\section{Evaluasi Product}

Berdasarkan data dokumentasi hasil evaluasi yang diperoleh WB program KUM, ternyata prestasi belajarnya sudah cukup tinggi. Secara keseluruhan rata-rata skor yang dicapai WB cukup tinggi sesuai dengan kompetensi dasar program KUM. Dari beberapa aspek yang dinilai kebanyakan skor tertinggi ada pada bahan penilaian berhitung, hal ini disebabkan karena kebanyakan WB dalam kehidupan sehari-hari tidak lepas dari hitung-hitungan seperti menghitung uang, menghitung hasil panen pertaniannya, dan lain-lain.

Berdasarkan

ketentuan keberhasilan program KUM yang menyebutkan bahwa dalam program tersebut harus dilakukan penilaian kepada WB untuk mengukur pencapaian WB dalam memperoleh kompetensi keaksaraan berdasarkan Standar Kompetensi Keaksaraan Usaha Mandiri (SK-KUM). Selain itu penilain bertujuan untuk dapat mengetahui jumlah WB yang berhak mendapatkan surat keterangan berupa sertifikat yang diberikan oleh penyelenggara program KUM kepada WB yang telah selesai mengikuti program keaksaraan usaha mandiri.

Berdasarkan keterangan dari WB bahwa program KUM yang diikutinya memberikan manfaat yang baik, karena dengan mengikuti program tersebut WB dapat memperoleh keterampilan yang dapat dikembangkan dan dapat untuk menambah penghasilan keluarganya. Oleh karena itu, dimasa yang akan datang program KUM ini masih perlu 
dipertahankan dan semakin diperbaiki kualitasnya.

Dengan demikian yang menjadi konsekuensinya adalah tuntutan perbaikan kualitas dari program KUM itu sendiri. Kemanfaatan yang dirasakan masyarakat khususnya warga belajar peserta program, perlu direspon dalam bentuk kualitas penyelenggaraannya yang lebih baik lagi. Sehingga dimasa yang akan datang sudah seharusnyalah program ini dapat diberikan perhatian yang lebih baik. Berbagai pihak harus lebih meningkatkan perhatiannya pada penyelenggaraan program ini, baik pemerintah, masyarakat, maupun dari penyelenggara itu sendiri. Tanpa perhatian dan dukungan dari seluruh komponen masyarakat maka program KUM ini mungkin tidak akan mampu memberikan manfaat yang optimal.

\section{KESIMPULAN}

Berdasarkan hasil dan pembahasan pada Bab IV, maka dapat dirumuskan kesimpulan sebagai berikut:

1. Kebutuhan masyarakat terhadap penyelenggaraan program KUM cukup tinggi, karena faktor ekonomi dan kesesuaian jam belajar yang tidak berbenturan dengan jam kerja WB serta selain belajar calistung juga diberikan keterampilan.

2. Penyelenggaraan program KUM dilaksanakan pada lingkungan Lembaga PAUD yang sesuai, yaitu 
memiliki perbandingan yang sesuai dengan jumlah WB.

8. Kepala dan Guru PAUD dapat mengelola kegiatan pembelajaran. Namun ada beberapa kekurang-an yang perlu diperbaiki, yaitu persiapan mengajar dan penggunaan alat peraga.

9. Aktivitas WB pada proses pembelajaran baik di kelas maupun di luar kelas belum optimal karena WB kurang aktif mengemukakan pendapat dan mengerjakan tugas yang diberikan Kepala dan Guru PAUD.

10. Secara umum pencapaian prestasi belajar WB program KUM dilihat dari hasil evaluasi sudah cukup tinggi telah memberikan manfaat bagi kehidupan WB-nya.

\section{DAFTAR PUSTAKA}

Azwar, S. (2006). Reliabilitas dan Validitas. Yogyakarta: Pustaka Pelajar.

Archer, D. \& Cotting, S. (1995). Reflect mother manual: Regerated freirean literacy through empowering community techniques. London: Actionaid.

Bartin, T. (2006). Pendidikan orang dewasa sebagai basis pendidikan non formal. Jurnal Teknodik, 19, 154-171.

Bhola, H.S. (1994). A sources book for literacy work. Perspective from the grass roots.London: Jessica Kingsley Publishers/UNESCO Publishing.
Bozarth, J. (2008). From Analysis to Evaluation: Tools, Tips, and Techniques for Trainers. San Francisco: Pfeiffer.

Depdiknas (2003). Undang-undang RI No. 20 tahun 2003 tentang sistem pendidikan nasional (Sisdiknas). Jakarta:

Departemen Pendidikan Nasional.

(2014). Laporan

Akuntabilitas Kinerja Ditjen PAUDNI Tahun 2017.Jakarta: Direktorat Jenderal Pendidikan Anak Usia Dini, Nonformal dan Informal.

Hiryanto, (2010). Pengendalian Mutu Program Pendidikan Nonformal dan Informal.Yogyakarta: Bahan Diklat Fungsional Penilik.

Kahar, A. (2000). Pendekatan Keaksaraan Fungsional dalam Proses Pembelajaran pada Kelompok Belajar Pemberantasan Buta Aksara. Tesis tidak dipublikasikan. UNY.

Komar, O. (2006). Filsafat pendidikan nonformal. Bandung: $\quad \mathrm{CV}$. Pustaka Setia.

Kusnadi. (2005). Pendidikan keaksaraan. filosofi, strategi, implementasi. Jakarta:

Depdiknas.

Pemprov Jawa Timur. (2012). Modul pendidikan keaksaraan usaha mandiri.Semarang: Dinas Pendidikan Provinsi Jawa Timur.

Peraturan Pemerintah Nomor 19 Tahun 2005 tentang Standar Nasional Pendidikan. 
Peraturan Menteri Pendayagunaan Aparatur Negara dan Reformasi Birokrasi Nomor 14 Tahun 2010 tentang Jabatan Fungsional Penilik dan Angka Kreditnya.

Peraturan Menteri Pendidikan dan Kebudayaan Nomor 38 Tahun 2017 tentang Petunjuk Teknis Jabatan Fungsional Penilik dan Angka Kreditnya.

Posavac, E. \& Carey, RG. (1985). Program evaluation method and case study. United State of America: Prentice Hall.Inc.

Rogers, A. (2005). Non-Formal Education. New York: Springer Science+Business Media. Inc.

Rouse, M. (2011). Total Quality Management.http://whatis.tec htarget.com/ definition/qualitycontrol-QC.Diunduh 6 Maret 2014.

Sholikhatun.(2012). Subjek, Sasaran, Prinsip, dan Alat Evaluasi.http://sholikhatun29. blogspot.com/2012/11/subjeksasaran-prinsip-dan-alatevaluasi.html. Diunduh 6 Maret 2014.

Sihombing, U. (2000). Pendidikan luar sekolah manajemen strategi. Jakarta: PD Mahkota.

Sodiq, A.K. (2007). Pendidikan keaksaraan untuk mencerdaskan kehidupan masyarakat. Jurnal IImiah Visi PTK-PNF, vol.2, No. 1, 23-27.

Sudjana, D. (2000). Pendidikan luar sekolah, wawasan, sejarah perkembangan, falsafah dan teori pendukung asas. Bandung: Nusantara Press.

(2006). Evaluasi program pendidikan luar sekolah.Bandung: PT Remaja Rosdakarya.

Suharsimi, (2012).Evaluasi program pendidikan.http://anannur.blogspot.com/2012/ 01/evaluasi-program-pendidikanprof-dr.html. Diunduh 4 Maret 2014.

Uhar, S.P. Pendidikan Nonformal. http://uharsputra.wordpress.co $\mathrm{m} /$ pendidikan/ pendidikannonformal/.Diunduh 6 Maret 2014

Wirawan. (2011). Evaluasi: Teori, Model, Standar, Aplikasi, dan Profesi. Jakarta: PT Raja Grafindo Persada.

Worthen, B.R. \& Sanders, J.R. (1973). Educational evaluation: Theory and practice.Woshington, Ohio: Charles A. Jones Publishing Compani.

Wisnu, A.P. (2008). Evaluasi Program Keaksaraan Fungsional di Kecamatan Kaloran Kabupaten Gresik Jawa Timur. Tesis tidak dipublikasikan. UNY. 